\title{
Combining AHP with Grey Relational Grade in the Evaluation of School Management
}

\author{
Hui Zhou \\ Department of art design \\ Xiamen Institute of Software Technology \\ Xiamen, China
}

\author{
Chianglung Lin \\ City College \\ Dongguan University of Technology \\ Dongguan, China
}

\begin{abstract}
With the trend of depopulation emerging, technology college/universities in Taiwan are hard pressed by the ever-decreasing student enrollments. A lot of educational problems arise, consequently. Also to blame are national colleges/universities, which endeavor to recruit as many students as possible. Private colleges/universities, which are trapped in student recruitment, have difficulty in school management. As a result, more efforts need to be made to raise the brand value and visibility of the school. The present study integrates analytic hierarchy process to grey relational analysis. Analytic hierarchy process is applied to obtain the weight of individual factors in each hierarchy. On the other hand, the grey System theory is implemented to analyze the factor weight where numerical values are found to be true, thus raising data visibility. Grey relational degree is used to calculate the measure between the discrete series. Based on the 2013 data of departments of a technology college in mid-Taiwan, the researcher assesses the management performance of each department. This study can serve as a guide for school improvement and pave the way for school management. The present study leads to a better understand of how resources are utilized and allocated. Also, it enables each department to enhance its internal and external competitiveness. Data analysis shows that of all departments under assessment, G10 ranks No.1 in management performance. It excels in issues regarding academic affairs, student affairs and technological cooperation and manifests significant difference from other departments.
\end{abstract}

Keywords-Depopulation emerging; Analytic Hierarchy process; Grey relational analysis

\section{INTRODUCTION}

Due to the change of external environment and the decreasing youth population, 5-year Junior Colleges and 4year Colleges in Taiwan have tremendous difficulty recruiting students. The number of students registering for 4Year and 2-Year Technology College Exam has dropped by $35 \%$ over the past 10 years. Whereas national colleges/universities are recruiting more and more students, private institutes are recruiting fewer and fewer students. Obviously, private institutes are having difficulty in student recruitment and school management. Due to liberalization of higher education, the number of colleges/universities has been on the increase over the past ten years. This policy has stranded private institutes in a dilemma. Therefore, private institutes should try their best to spend more efforts on school management and promote brand value and visibility of the school.

Assessment of school management performance is quite a complex issue. It is more so when it comes to technology college/university. Technology colleges/universities, which were previously known as junior colleges, are immediately faced with accreditation and the reality of educational environment. Due to the trend of degeneration, liberalization of higher education, and decreasing ratio of vocational high schools, the general public has tended to regard vocational education as a secondary choice. Therefore, to cope with challenge for survival, technology colleges/universities need to be assessed as regards school management performance. This study can help school administrators develop a better understanding of school improvement and manage their schools in a right direction. Through assessing management performance of a department, we can understand how resources are utilized and allocated, and therefore enhance its internal and external competitiveness.

Over the past few years there has been little research dealing with management performance assessment of departments of technology colleges/universities. Neither has there been any study which establishes an assessment model of total departmental management performance. The present study aims to assess and compare departments of a technology college as to their management performance. The research result helps understand the relative developmental level of a department and the status it assumes in the total school development. By referring to this study, schools can effectively adopt relevant measures to obtain more resources. Also, schools can have a better understanding of departmental management performance and efficacy and therefore encourage inter-department competition. The assessment may serve as a guide for allocating resources, including manpower and finance.

Deng initiated the grey system theory, which aims to undergo, in circumstances where data incompleteness, uncertainty of system model and fuzzy operation are found to exist, system relational analysis and establishment of model, and prediction and decision [1]. In a sense, the grey system theory is applied to process system relational analysis and model establishment. In addition, through prediction and decision methods, it can explore and help understand the system. It effectively deals with problems such as 
uncertainty, multivariate input, discrete values and data incompleteness. Grey relational analysis (GRA) aims to investigate the relational grade between two discrete sequences of numbers. It makes use of measures of dispersion to as a measure of distance. The analytic hierarchy process (AHP), first developed by Saaty in the 70s[2], is a famous decision analysis method. With its theoretical simplicity, AHP can be manipulated with ease. Based on opinions collected from experts, it can solve complex decision problems. It is in essence a practical method.

Scholars have over the past few years been engaged in applying GRA to investigate educational problems. GRA has been applied to the strategy of test question election. It effectively prevents errors resulting from random sampling based on the random number [3]. Lin et al. applied it to test question selection. According to them, the selection process is divided into two stages including primary selection and replacement of test questions. Different strategies are respectively proposed for the two stages. Primary selection of test questions includes entropy of target value average and random sampling. With respect to replacement of test questions, there are Grey relational replacement of test questions, Grey relational weight replacement and parameter correction replacement. However, research of test questions plays at best a minor part in assessment of higher education [4].

Over the past few years, scholars have been gradually interested in applying GRA to investigation of the quality of instructional service and total learning satisfaction [5]. By referring 10 quality attributes of the PZB model, which exert influence on instructional service quality and total learning satisfaction, they processed Grey relational grade of these attributes. They also verified instructional service quality and total learning satisfaction. Wang et al. applied GRA to investigation of the relations between emotional quotients (EQs) and conflict management manifested by school administrators. They proposed selection indexes of school administrators [6]. Concerning college/university accreditation, Chen et al. proposed that accreditation be based on data derived from GRA. The constructs and criteria of this model can also apply to teacher's performance assessment [7]. As the weight needs to be dependent on the features and needs of each department or each school, we should therefore emphasize the diversity and completeness of teacher's performance assessment.

However, the constructs of college/university assessment go far beyond the teacher as instructor. The assessment items included in the present study are instruction, guidance and counseling, service, research and soft and hard-ware. It applies both AHP and GRA for analysis. AHP is first applied for hierarchy construction. The school administrators, on the basis of the needs and importance of their units, identify the impact factors and establish hierarchy relations. Pairwise comparison is implemented to find the relative importance of the decision attribute of each hierarchy. Pairwise comparison matrix is therefore established to calculate the eigenvalue and eigenvectors of the matrix. The numerical values are subject to treatment and visibility enhancement. Next, Grey relational grade is applied to calculate the measure between discrete series. Based on the 2013 data of all departments, the researcher conducts an investigation of the management performance of each department by combining AHP and GRA.

The second section of the present paper provides a detailed description of AHP and grey relational analysis. The third part develops the index system of departmental management performance assessment. Finally, in the last section, conclusions are drawn based on the finding.

\section{AHP AND GREY RELATIONAL GRADE}

The AHP, first developed by Saaty in the 1970s, is a famous decision analysis method. With its theoretical simplicity, AHP can be manipulated with ease. Based on opinions collected from experts, it can solve complex decision problems. It is in essence a practical method. The paper combines AHP with grey relational grade method to promote the reliability of the evaluation.

\section{A. Procedure of AHP Application}

To deal with problems effectively, we are supposed to analyze them systematically. AHP deals with problems in an easy and practical manner. Applying AHP to problem solution generally goes through the following 7 steps [8].

1) Define the problem: The larger the system where the problem is located, the better. Elements which influence the problem all need to be taken into consideration. Meantime, when establishing a planning group, we also have to define the scope of the problem.

2) Establish hierarchy structure: Through brainstorming, the members of the planning group come up with evaluation criteria and sub-criteria, the characteristics of alternative cases, and alternative cases. All of them inevitably exert influence on the problem. Based on the principle of AHP, the present study proposes evaluation index system of local cultural museums. "Fig. 1" shows the system.

3) Design questionnaire and survey: By pairwise comparison is meant that, assuming a certain element of the upper hierarchy is regarded as the evaluation basis, each element of the dominated hierarchy is subject to comparison with all other elements of the same hierarchy. The questionnaire is developed based on pairwise comparison. By referring to the 9-point scale, decision makers or the decision group provide the grade of each pair of elements under comparison.

4) Establish pairwise comparison matrix: By referring to the Liker 5-point scale, the researcher divides the AHP evaluation scale into 5 items (degree of importance), namely equally important, somewhat important, very important, extremely important and absolutely important, which respectively assumes 1, 3, 5, 7 and 9 points. Four additional items are respectively placed between 1 and 3, 3 and 5, 5 and 7, 7 and 9, and respectively assume 2, 4, 6, and 8 points. "Table I" shows the meaning of each item. 
Pairwise comparison is conducted between an element of the (dominated) hierarchy and all other elements of the same hierarchy. The numerical values for pairwise comparison are respectively $1 / 9,1 / 8, \ldots \ldots .1 / 2,1,2,3 \ldots \ldots .8,9$.

$$
A=\left(\begin{array}{cccc}
a_{11} & a_{12} & \cdots & a_{1 j} \\
a_{21} & a_{22} & \cdots & a_{2 j} \\
\vdots & \vdots & \ddots & \vdots \\
a_{i 1} & a_{i 2} & \cdots & a_{i j}
\end{array}\right), a_{i i}=1, a_{i j}=\frac{1}{a_{j i}}, a_{i k}=a_{i j} a_{j k}
$$

TABLE I. Evaluation MEANing OF AHP

\begin{tabular}{|l|l|l|}
\hline \multicolumn{3}{|c|}{ The Fundamental Scale for Pairwise Comparisons } \\
\hline $\begin{array}{c}\text { Intensity } \\
\text { of } \\
\text { Importan } \\
\boldsymbol{c e}\end{array}$ & \multicolumn{1}{|c|}{ Definition } & \multicolumn{1}{c|}{ Explanation } \\
\hline 1 & $\begin{array}{l}\text { Equal } \\
\text { importance }\end{array}$ & Two elements contribute equally to the objective \\
\hline 3 & $\begin{array}{l}\text { Moderate } \\
\text { importance }\end{array}$ & Experience and judgment slightly favor one element over another \\
\hline 5 & $\begin{array}{l}\text { Strong } \\
\text { importance }\end{array}$ & Experience and judgment strongly favor one element over another \\
\hline 7 & $\begin{array}{l}\text { Very strong } \\
\text { importance }\end{array}$ & $\begin{array}{l}\text { One element is favored very strongly over another, its dominance } \\
\text { is demonstrate in practice }\end{array}$ \\
\hline 9 & $\begin{array}{l}\text { Extreme } \\
\text { importance }\end{array}$ & $\begin{array}{l}\text { The evidence favoring one element over another is of the highest } \\
\text { possible order of affirmation }\end{array}$ \\
\hline $\begin{array}{l}\text { Intensities of 2,4,6 and } 8 \text { can be used to express intermediate values. Intensities 1.1,1.2, 1.3, etc. } \\
\text { can be used for elements that are very close in importance. }\end{array}$ \\
\hline
\end{tabular}

5) Eigenvectors and eigenvalues: The weight of each element of the hierarchy ( $\left.W_{i}\right)$ is derived after the establishment of the pairwise comparison matrix.

$$
\begin{gathered}
A W=\lambda_{\max } W \\
W_{i}=\frac{\sqrt[n]{\sum_{j=1}^{n} a_{i j}}}{\sum_{i=1}^{n} \sqrt[n]{\sum_{j=1}^{n} a_{i j}}} i, j=1,2,3, \cdots, n
\end{gathered}
$$

$\lambda_{\max }$ : Maximum eigenvalue of $\mathrm{A}$

6) Test of matrix consistency: A pairwise comparison matrix is established based on the result derived from the questionnaire survey. The eigenvectors and eigenvalues of each pairwise comparison matrix are obtained by using the calculator. Meantime, test of matrix consistency is also applied. If two decisions made at different points of time are found to differ from each other, matrix consistency is regarded as failing to meet the requirements.

$$
\text { C.I. }=\frac{\lambda_{\max .}-n}{n-1}
$$

C.I. $=0$ refers to consistency between two judgments, and C.I.>0 refers to inconsistency between two judgments. The error is acceptable where C.I. is smaller than 0.1 .

7) Test of hierarchy consistency: Once the consistency degree of each pairwise comparison matrix meets the requirements, we need further to test the structural consistency of the hierarchy. Again, if the structural consistency of the hierarchy fails to meet the requirements, there exists a problem with the relations between the elements of the hierarchy. It is necessary, therefore, to conduct analysis of elements and relations.

$$
C R=\frac{C I}{R I}
$$

In both cases, including evaluation of decision makers' judgment and test of the hierarchical structure, the consistency values, according to Saaty, are supposed to fall approximately on 0.1 (in general, C.R.<0.1). Thus, consistency won't be open to questioning.

\section{TABLE II. R.I VALUES}

\begin{tabular}{|c|l|l|l|l|l|l|l|l|l|l|}
\hline Rank & 1 & 2 & 3 & 4 & 5 & 6 & 7 & 8 & 9 & 10 \\
\hline R.I. & 0.00 & 0.00 & 0.58 & 0.90 & 1.12 & 1.24 & 1.32 & 1.41 & 1.45 & 1.49 \\
\hline
\end{tabular}

\section{B. Grey Relational Analysis}

1) Grey generating: The word "grey generating" in the grey system theory means to add new information for the system's needs. In other words, it means that, based on the processed data find the rule of data. In this paper, we based on the concept of loss function [9], to present three kinds of grey generating.

(1)Larger the better

$$
\begin{aligned}
& x_{i}^{*}(k) \approx k_{1}\left(x_{i}^{(0)}(k)-\min \cdot x_{i}^{(0)}(k)\right)^{2}, \quad k_{1}=\frac{1}{\left(\max \cdot x_{i}^{(0)}(k)-\min \cdot x_{i}^{(0)}(k)\right)^{2}} \\
& \quad(2) \text { Smaller the better } \\
& x_{i}^{*}(k) \approx k_{2}\left(x_{i}^{(0)}(k)-\max \cdot x_{i}^{(0)}(k)\right)^{2}, \quad k_{1}=\frac{1}{\left(\min \cdot x_{i}^{(0)}(k)-\max \cdot x_{i}^{(0)}(k)\right)^{2}}
\end{aligned}
$$

(3)Nominal the better

$$
x_{i}^{*}(k) \approx 1-k\left(x_{i}^{*}(k)-O B\right)^{2}=\left\{\begin{array}{l}
1-k_{3}\left(x_{i}^{*}(k)-O B\right)^{2}, x_{i}^{*}(k) \leq O B \\
\Rightarrow k_{3}=\frac{1}{\left(\min \cdot x_{i}^{*}(k)-O B\right)^{2}} \\
1-k_{4}\left(x_{i}^{*}(k)-O B\right)^{2}, x_{i}^{*}(k) \geq O B \\
\Rightarrow k_{4}=\frac{1}{\left(\max \cdot x_{i}^{*}(k)-O B\right)^{2}}
\end{array}\right.
$$


where: i. $x_{i}^{*}(k)$ : generated value.

ii. $x_{i}^{(0)}(k)$ : Original data

iii. $\max _{\text {alli }} \cdot x_{i}^{(0)}(k)$ : The maximum of original data

Iv. $\min _{\text {alli }} . x_{i}^{(0)}(k)$ : The minimum of original data

v. $O B$ : target value, $O_{1}=\max _{\text {alli }} \cdot x_{i}^{(0)}(k)-O B, O_{2}=O B-\min _{\text {alli }} \cdot x_{i}^{(0)}(k)$

\section{Grey Relational Grade}

During the three decades, many scholars according to the four axioms in grey relational grade to propose different types of grey relational grade, the widely used in the relevant fields, the four difference grey relational grade are shown below [10].

(1) Wu's grey relational grade

$$
\begin{gathered}
\Gamma_{0 i}=\Gamma\left(x_{0}, x_{i}\right)=\frac{\Delta_{\min .}+\Delta_{\max } .}{\bar{\Delta}_{0 i}+\Delta_{\max }}, \text { in which } \\
\bar{\Delta}_{0 i}=\sqrt{\frac{1}{n} \sum_{k=1}^{n}\left[\Delta_{0 i}(k)\right]^{2}}
\end{gathered}
$$

(2) Wen's grey relational grade $\Gamma_{0 i}=\Gamma\left(x_{0}, x_{i}\right)=\frac{\Delta_{\min .}+\Delta_{\max }}{\bar{\Delta}_{0 i}+\Delta_{\max }}$. in which

$$
\bar{\Delta}_{0 i}=\left\{\frac{1}{n} \sum_{k=1}^{n}\left[\Delta_{0 i}(k)\right]\right\}
$$

(3) Hsia's grey relational grade $\Gamma_{0 i}=\Gamma\left(x_{0}, x_{i}\right)=\frac{\Delta_{\max .}-\bar{\Delta}_{0 i}}{\Delta_{\max .}-\Delta_{\min }}$ in which

$$
\bar{\Delta}_{0 i}=\left\{\frac{1}{n} \sum_{k=1}^{n}\left[\Delta_{0 i}(k)\right]\right\}
$$

(4) Nagai's grey relational grade

$$
\begin{gathered}
\Gamma_{0 i}=\Gamma\left(x_{0}(k), x_{i}(k)\right)=\frac{\bar{\Delta}_{\max .}-\bar{\Delta}_{0 i}}{\bar{\Delta}_{\max .}-\bar{\Delta}_{\min } .} \text { in which } \\
\bar{\Delta}_{0 i}=\left\|x_{0 i}\right\|_{\rho}=\left(\sum_{k=1}^{n}\left[\Delta_{0 i}(k)\right]^{2}\right)^{\frac{1}{2}} \text { (11) }
\end{gathered}
$$

where $: \bar{\Delta}_{\max }$ and $\bar{\Delta}_{\min }$. are the maximum and minimum of $\bar{\Delta}_{0 i}$.

\section{Grey Relational Rank}

After the grey relational grade is calculated, according the value, we can rank the sequence, and this procedure is called grey relational rank. For reference sequences $x_{0}$, and inspected sequences are $x_{i}$, if $\Gamma\left(x_{0}, x_{i}\right) \geq \Gamma\left(x_{0}, x_{j}\right)$ then we found that under the reference sequence $x_{0}$, the grey relational rank of $x_{i}$ is greater than grey relational rank of ${ }^{x_{j}}$.

\section{REAL EXAMPLE}

The researcher targets 10 departments of a 4-year college located in northern Taiwan. They are Department of Applied Cosmetology, Department of Computer Engineering Application, Department of Architecture, Department of Digital Living Innovation, Department of Creative Product and Technological Application, Department of Marketing and Logistics, Department of Finance and Insurance, Department of Information Management, Department of Foreign Languages, and Department of Health and Leisure Management. As the content of the indexes in the present study may involve confidential information related to school funds, the researcher regards it necessary, in view of academic ethics, not to identify the name of each department under investigation. Each of the ten departments is randomly assigned one of the following ten code numbers: G1, G2, G3, G4, G5, G6, G7, G8, G9 and G10. The inter-departmental comparison was conducted incognito, i.e. none of them are aware of being compared with others.

This study focuses on assessing management performance of each individual department of a college. The researcher targets 10 departments as the research objects. The researcher refers to three MOE's 2013 subsidy plans for private technology colleges/universities and departments and compiles a list based on literature survey. The researcher also develops "management performance indexes of departments of technology colleges. The indexes include: A1 weighted student number, A2 accreditation grade, A3 performance of cooperative instruction with experts from business, A4 student achievement, B1 general student affairs, B2 achievement in labor education and service learning, B3 promotion of school physical education, B4 promotion of student affairs, C1 performance in total general affairs, D1 faculty structure, E1 promote student job opportunities, E2 number of certificates, E3 performance of student internship in business, E4 performance of school-business joint program, and E5 performance of technological development of school-business joint efforts. The 5 sequential capital letters, namely $\mathrm{A}, \mathrm{B}, \mathrm{C}, \mathrm{D}$, and $\mathrm{E}$, respectively refer to academic affairs office, student affairs office, general affairs office, personnel office and technological cooperation office. Each office sets up different assessment criteria. Also, each index is different from another in unit and quality characteristics (i.e. larger the better, LTB; smaller the better, STB; nominal the better). Therefore, the present study applies GRA to analyze and assess the ranking of each department. Forthcoming research may refer to the data provided by the present paper. School administrators may also refer to this study as a guiding model of management 
performance assessment. "Table III" shows the index system

of management performance assessment.

TABLE III. InDEX SYSTEM OF DEPARTMENTAL MANAGEMENT PERformanCE AsSESSMENT

\begin{tabular}{|c|c|c|}
\hline Level-1 & Level-2 & Level-3 \\
\hline \multirow{10}{*}{$\begin{array}{l}\text { A: } \\
\text { Academic Affairs Office }\end{array}$} & \multirow{6}{*}{$\mathrm{A}_{1}$ : Weighted student number } & $\mathrm{A}_{11}:$ Fill-time student number \\
\hline & & $\mathrm{A}_{12}:$ Part-time student number(evening \& continuing education) \\
\hline & & $\mathrm{A}_{13}$ : 2-year college full-time student number \\
\hline & & $\mathrm{A}_{14}: 4^{\text {th }}$ and $5^{\text {th }}$ year students of 5 -year junior college \\
\hline & & $\mathrm{A}_{15}: 1^{\mathrm{st}}-3^{\text {rd }}$ year students of 5 -year junior college \\
\hline & & $\mathrm{A}_{16}:$ Student number of continuing education of junior college \\
\hline & $\mathrm{A}_{2}$ : Assessment grade & $\mathrm{A}_{21}$ : Comprehensive assessment grade by MOE \\
\hline & \multirow{2}{*}{$\begin{array}{l}A_{3}: \text { Performance of cooperative instruction } \\
\text { with experts from business }\end{array}$} & $\mathrm{A}_{31}$ : Total instructional hours \\
\hline & & $\mathrm{A}_{32}:$ Total courses offered \\
\hline & $\mathrm{A}_{4}$ : Student achievement & $\mathrm{A}_{41}$ : Students' participation in competition and awards \\
\hline \multirow{11}{*}{$\begin{array}{c}\text { B: } \\
\text { Student Affairs Office }\end{array}$} & $\mathrm{B}_{1}$ : General student affairs & $\mathrm{B}_{11}$ : Achievement in total student affairs and guidance \\
\hline & \multirow{2}{*}{$\begin{array}{l}\mathrm{B}_{2}: \text { Achievement in labor education and service } \\
\text { learning }\end{array}$} & $\mathrm{B}_{21}$ : Hours of service learning \\
\hline & & $\mathrm{B}_{22}$ : Subsidy cases from the government \\
\hline & \multirow{5}{*}{$\mathrm{B}_{3}$ : Promotion of school physical education } & $\mathrm{B}_{31}$ : Intra-collegiate sports contest \\
\hline & & $\mathrm{B}_{32}:$ Inter-department contest \\
\hline & & $\mathrm{B}_{33}:$ Freshman cup \\
\hline & & $\mathrm{B}_{34}$ : Games for fun \\
\hline & & $\mathrm{B}_{35}:$ Teacher-student physical fitness examination \\
\hline & \multirow{3}{*}{$\mathrm{B}_{4}$ : Promotion of student affairs } & $\mathrm{B}_{41}:$ Character education \\
\hline & & $\mathrm{B}_{42}:$ Hife education \\
\hline & & $\mathrm{B}_{43}:$ Gender equality education \\
\hline \multirow{2}{*}{$\begin{array}{c}C: \\
\text { General Affairs Office }\end{array}$} & \multirow{2}{*}{$\mathrm{C}_{1}$ : Performance in total general affairs } & $\mathrm{C}_{11}$ : Property care and maintenance \\
\hline & & $\mathrm{C}_{12}$ : Property utilization \\
\hline $\begin{array}{c}D: \\
\text { Personnel Office }\end{array}$ & $\mathrm{D}_{1}$ : Faculty structure & $\mathrm{D}_{11}$ : Student-teacher ratio \\
\hline \multirow{11}{*}{$\begin{array}{c}E: \\
\text { Office of Technological } \\
\text { Cooperation }\end{array}$} & \multirow{2}{*}{$E_{1}:$ Promote student job opportunities } & $E_{11}$ : Provide employee engagement activities \\
\hline & & $\mathrm{E}_{12}$ : Employment rate of graduates \\
\hline & \multirow{2}{*}{$E_{2}:$ Number of certificates } & $E_{21}$ : Language certificates from the government \\
\hline & & $\mathrm{E}_{22}$ : Other certificates \\
\hline & \multirow{2}{*}{$\begin{array}{l}E_{3}: \text { Performance of student internship in } \\
\text { business }\end{array}$} & $E_{31}:$ Rate of semester-based internships \\
\hline & & $\mathrm{E}_{32}:$ Rate of summer internships \\
\hline & \multirow{2}{*}{$\begin{array}{l}E_{4}: \text { Performance of school-business joint } \\
\text { program }\end{array}$} & $\mathrm{E}_{41}:$ Number classes offered \\
\hline & & $E_{42}$ : Amount of money for class \\
\hline & \multirow{3}{*}{$\begin{array}{l}E_{5} \text { : Performance of technological development } \\
\text { of school-business joint efforts }\end{array}$} & $\begin{array}{l}\mathrm{E}_{51} \text { : Amount of money for joint effort program } \\
\mathrm{F}_{5} \cdot \text { Patent anplications }\end{array}$ \\
\hline & & $\mathrm{E}_{53}$ : Published papers \\
\hline & & $\mathrm{E}_{54}$ : Publication of special books \\
\hline
\end{tabular}

\section{A. Establish Hierarchy Structure of Assessment Objects}

The researcher applies AHP for in-depth investigation. Through repeated discourses, the researcher proceeds hierarchy analysis. This aims to keep elements in the same hierarchy from having overlapping meaning. There is a father-son relationship between the elements in the upper hierarchy and the elements in the dominated hierarchy. The elements in the lowest hierarchy are the evaluation indexes being sought for.

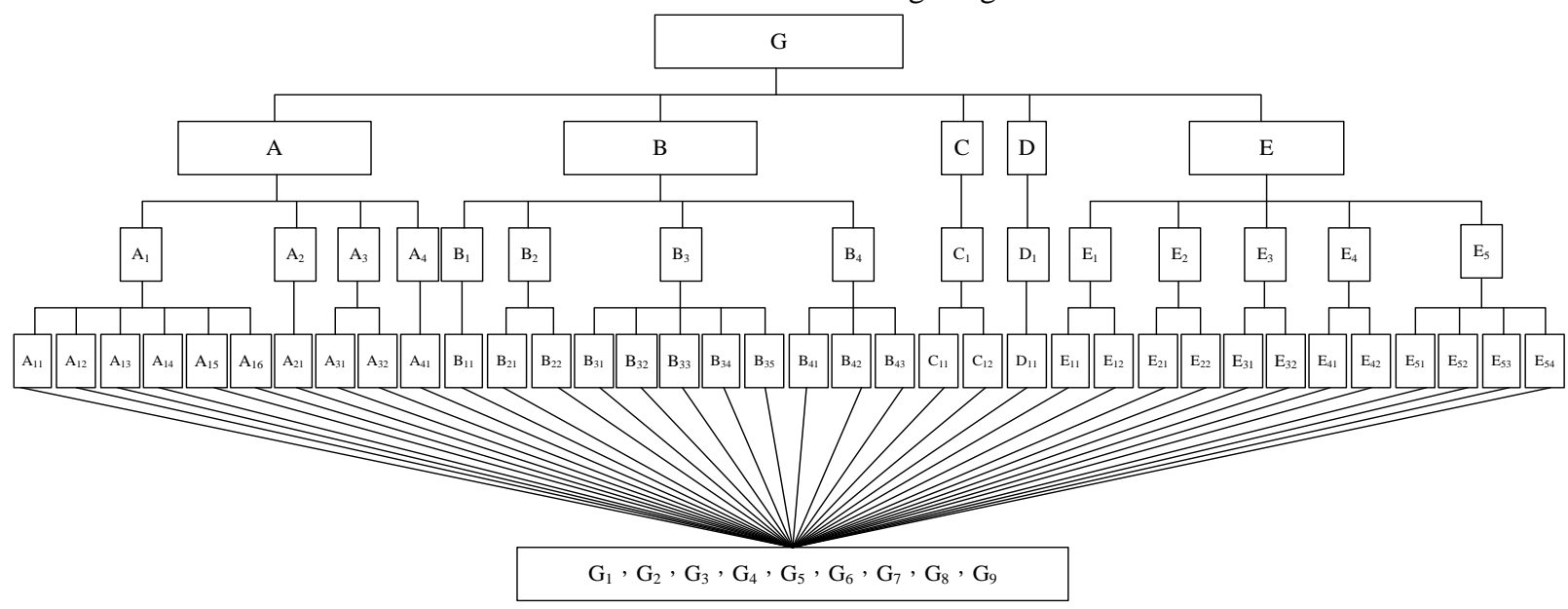

Fig. 1. The analytic hierarchy of evaluation. 


\section{B. Establish Judgment Matrix and Certify the Weight of Assessment Index}

Administrators decide their own assessment criteria based on the development and importance of their own offices. The researcher implements pairwise comparison to find the relative weight of the decision attribute of each hierarchy, whereupon the comparison matrix is established. After calculating the eigenvalue and eigenvectors of the matrix, and testing the matrix consistency and hierarch consistency, the researcher obtains the weight of each attribute.

\section{1) Comparison matrix $G$-Level-1}

TABLE IV. G-LEVEl-1 COMPARISON MATRIX AND WEIGHTING

\begin{tabular}{|c|c|c|c|c|c|c|}
\hline & \multicolumn{1}{|c|}{$\mathbf{A}$} & $\mathbf{B}$ & $\mathbf{C}$ & $\mathbf{D}$ & $\mathbf{E}$ & $\begin{array}{c}\text { Weigh } \\
\text { ting }\end{array}$ \\
\hline $\boldsymbol{A}$ & 1.000 & 5.000 & 5.000 & 7.000 & 2.000 & 0.456 \\
\hline $\boldsymbol{B}$ & 0.200 & 1.000 & 1.000 & 3.000 & 0.250 & 0.097 \\
\hline $\boldsymbol{C}$ & 0.200 & 1.000 & 1.000 & 3.000 & 0.250 & 0.097 \\
\hline $\boldsymbol{D}$ & 0.143 & 0.333 & 0.333 & 1.000 & 0.167 & 0.043 \\
\hline $\boldsymbol{E}$ & 0.500 & 4.000 & 4.000 & 6.000 & 1.000 & 0.307 \\
\hline$\lambda \max =5.115 \mathrm{CI}=0.029 \mathrm{CR}=0.026$ \\
\hline
\end{tabular}

2) Comparison matrix $A-A_{i}$

TABLE V. A-Ai COMPARISON MATRIX AND WEIGHTING

\begin{tabular}{|c|c|c|c|c|c|}
\hline & $\mathbf{A}_{\mathbf{1}}$ & $\mathbf{A}_{\mathbf{2}}$ & $\mathbf{A}_{\mathbf{3}}$ & $\mathbf{A}_{\mathbf{4}}$ & $\begin{array}{c}\text { Weigh } \\
\text { ting }\end{array}$ \\
\hline $\boldsymbol{A}_{\boldsymbol{1}}$ & 1.000 & 5.000 & 5.000 & 7.000 & 0.728 \\
\hline $\boldsymbol{A}_{\mathbf{2}}$ & 0.200 & 1.000 & 1.000 & 3.000 & 0.121 \\
\hline $\boldsymbol{A}_{\mathbf{3}}$ & 0.200 & 1.000 & 1.000 & 3.000 & 0.065 \\
\hline $\boldsymbol{A}_{\mathbf{4}}$ & 0.143 & 0.333 & 0.333 & 1.000 & 0.086 \\
\hline$\lambda \max =4.126 \mathrm{CI}=0.042 \mathrm{CR}=0.047$ \\
\hline
\end{tabular}

3) Comparison matrix $B-B_{i}$

TABLE VI. B-BI COMPARISON MATRIX AND WEIGHTING

\begin{tabular}{|c|c|c|c|c|c|}
\hline & B1 & B2 & B3 & B4 & $\begin{array}{c}\text { Weight } \\
\text { ing }\end{array}$ \\
\hline $\boldsymbol{B}_{\boldsymbol{1}}$ & 1.000 & 0.200 & 0.333 & 0.500 & 0.084 \\
\hline $\boldsymbol{B}_{2}$ & 5.000 & 1.000 & 3.000 & 4.000 & 0.545 \\
\hline $\boldsymbol{B}_{3}$ & 3.000 & 0.333 & 1.000 & 2.000 & 0.233 \\
\hline $\boldsymbol{B}_{4}$ & 2.000 & 0.250 & 0.500 & 1.000 & 0.138 \\
\hline$\lambda \max =4.126 \mathrm{CI}=0.042 \mathrm{CR}=0.047$ \\
\hline
\end{tabular}

4. Comparison matrix E- $\mathrm{E}_{i}$

TABLE VII. E-EI COMPARISON MATRIX AND WEIGHTING

\begin{tabular}{|c|c|c|c|c|c|c|}
\hline & E1 & E2 & E3 & E4 & E5 & $\begin{array}{c}\text { Weigh } \\
\text { ting }\end{array}$ \\
\hline $\boldsymbol{E}_{\boldsymbol{1}}$ & 1.000 & 0.200 & 0.200 & 1.000 & 0.111 & 0.041 \\
\hline $\boldsymbol{E}_{\boldsymbol{1}}$ & 5.000 & 1.000 & 3.000 & 5.000 & 0.200 & 0.210 \\
\hline $\boldsymbol{E}_{\boldsymbol{1}}$ & 3.000 & 0.333 & 1.000 & 3.000 & 0.143 & 0.103 \\
\hline $\boldsymbol{E}_{\boldsymbol{1}}$ & 1.000 & 0.200 & 0.333 & 1.000 & 0.111 & 0.046 \\
\hline $\boldsymbol{E}_{\boldsymbol{5}}$ & 9.000 & 5.000 & 7.000 & 9.000 & 1.000 & 0.599 \\
\hline$\lambda \mathrm{mEx}=5.137 \mathrm{CI}=0.034 \mathrm{CR}=0.031$ \\
\hline
\end{tabular}

From "Table IV" to "Table VII" indicate that each comparison judgment matrix satisfies matrix and hierarchy consistency. According to the principle of AHP, the weight of index system is regarded as reasonable. It can effectively measure the relative importance of management performance assessment index of each department. Then, the weight of each assessment index and the total weight are subject to calculation. "Table VIII" shows the result.
TABLE VIII. The Weighting of EACH EVAluation INDEX AND TOTAL WEIGHTING

\begin{tabular}{|c|c|c|c|c|c|c|}
\hline $\begin{array}{c}\text { Level- } \\
1\end{array}$ & W1 & $\begin{array}{c}\text { Level } \\
-2\end{array}$ & W2 & $\begin{array}{c}\text { Level- } \\
3\end{array}$ & W3 & WT \\
\hline \multirow{10}{*}{$A$} & \multirow{10}{*}{0.456} & \multirow[t]{6}{*}{$\mathrm{A}_{1}$} & \multirow{6}{*}{0.728} & $\mathrm{~A}_{11}$ & 0.448 & 0.149 \\
\hline & & & & $\mathrm{A}_{12}$ & 0.077 & 0.026 \\
\hline & & & & $A_{13}$ & 0.189 & 0.063 \\
\hline & & & & $\mathrm{A}_{14}$ & 0.174 & 0.058 \\
\hline & & & & $\mathrm{A}_{15}$ & 0.077 & 0.026 \\
\hline & & & & $\mathrm{A}_{16}$ & 0.035 & 0.012 \\
\hline & & $\mathrm{A}_{2}$ & 0.121 & $\mathrm{~A}_{21}$ & 1.000 & 0.055 \\
\hline & & \multirow[t]{2}{*}{$\mathrm{A}_{3}$} & \multirow{2}{*}{0.065} & $\mathrm{~A}_{31}$ & 0.500 & 0.015 \\
\hline & & & & $A_{32}$ & 0.500 & 0.015 \\
\hline & & $\mathrm{A}_{4}$ & 0.086 & $\mathrm{~A}_{41}$ & 1.000 & 0.039 \\
\hline \multirow{11}{*}{$B$} & \multirow{11}{*}{0.097} & $\mathrm{~B}_{1}$ & 0.084 & $\mathrm{~B}_{11}$ & 1.000 & 0.008 \\
\hline & & \multirow{2}{*}{$\mathrm{B}_{2}$} & \multirow{2}{*}{0.545} & $\mathrm{~B}_{21}$ & 0.500 & 0.006 \\
\hline & & & & $\mathrm{B}_{22}$ & 0.500 & 0.026 \\
\hline & & \multirow{5}{*}{$\mathrm{B}_{3}$} & \multirow{5}{*}{0.233} & $\mathrm{~B}_{31}$ & 0.463 & 0.010 \\
\hline & & & & $\mathrm{B}_{32}$ & 0.195 & 0.004 \\
\hline & & & & $\mathrm{B}_{33}$ & 0.195 & $0 . .004$ \\
\hline & & & & $\mathrm{B}_{34}$ & 0.073 & 0.002 \\
\hline & & & & $\mathrm{B}_{35}$ & 0.073 & 0.002 \\
\hline & & \multirow{3}{*}{$\mathrm{B}_{4}$} & \multirow{3}{*}{0.138} & $\mathrm{~B}_{41}$ & 0.333 & 0.004 \\
\hline & & & & $\mathrm{B}_{42}$ & 0.333 & 0.004 \\
\hline & & & & $\mathrm{B}_{43}$ & 0.333 & 0.004 \\
\hline \multirow{2}{*}{$C$} & \multirow{2}{*}{0.097} & \multirow{2}{*}{$\mathrm{C}_{1}$} & \multirow{2}{*}{1.000} & $\mathrm{C}_{11}$ & 0.500 & 0.049 \\
\hline & & & & $\mathrm{C}_{12}$ & 0.500 & 0.049 \\
\hline$D$ & 0.043 & $D_{1}$ & 1.000 & $\mathrm{D}_{11}$ & 1.000 & 0.043 \\
\hline \multirow{12}{*}{$E$} & \multirow{12}{*}{0.307} & \multirow[b]{2}{*}{$\mathrm{E}_{1}$} & \multirow[b]{2}{*}{0.041} & $E_{11}$ & 0.700 & 0.009 \\
\hline & & & & $E_{12}$ & 0.300 & 0.004 \\
\hline & & \multirow{2}{*}{$\mathrm{E}_{2}$} & \multirow{2}{*}{0.210} & $E_{21}$ & 0.700 & 0.045 \\
\hline & & & & $\mathrm{E}_{22}$ & 0.300 & 0.015 \\
\hline & & \multirow{2}{*}{$E_{3}$} & \multirow{2}{*}{0.103} & $E_{31}$ & 0.300 & 0.009 \\
\hline & & & & $\mathrm{E}_{32}$ & 0.700 & 0.022 \\
\hline & & $E_{4}$ & 0.046 & $\mathrm{E}_{41}$ & 0.400 & 0.006 \\
\hline & & $\mathrm{E}_{4}$ & 0.046 & $E_{42}$ & 0.600 & 0.008 \\
\hline & & & & $E_{51}$ & 0.649 & 0.119 \\
\hline & & $\mathrm{F}_{\text {. }}$ & 0509 & $\mathrm{E}_{52}$ & 0.056 & 0.100 \\
\hline & & $\mathrm{E}_{5}$ & 0.599 & $\mathrm{E}_{53}$ & 0.148 & 0.027 \\
\hline & & & & $\mathrm{E}_{54}$ & 0.148 & 0.027 \\
\hline
\end{tabular}

\section{Grey Relational Grade}

After pre-processing of each department the final scores are shown in "Table IX".

E11 of "Table IX" assumes STB, while the others, LTB After calculating grey relational generation, Eq. (9) is applied to calculate grey relational grade. Each department's grey relational grade of performance and ranking as regards the items related to the 5 offices can be found in "Table X". 
TABLE IX. The Final SCORE OF EACh DePartment

\begin{tabular}{|c|c|c|c|c|c|c|c|c|c|c|}
\hline & $\mathbf{G}_{1}$ & $\mathbf{G}_{\mathbf{2}}$ & $\mathbf{G}_{\mathbf{3}}$ & $\mathbf{G}_{\mathbf{4}}$ & $\mathbf{G}_{5}$ & $\mathbf{G}_{6}$ & $\mathbf{G}_{7}$ & $\mathbf{G}_{8}$ & $\mathbf{G}_{9}$ & $\mathbf{G}_{1}$ \\
\hline$A_{11}$ & 267 & 135 & 165 & \begin{tabular}{|l|}
127 \\
\end{tabular} & 193 & 153 & 47 & 242 & 175 & 543 \\
\hline$A_{12}$ & 34 & 46 & 47 & 32 & 33 & 0 & 0 & 90 & 60 & 132 \\
\hline$A_{13}$ & 13 & 0 & 0 & 0 & 0 & 0 & 0 & 0 & 0 & 39 \\
\hline$A_{14}$ & 45 & 52 & 47 & 33 & 50 & 10 & 3 & 48 & 39 & \begin{tabular}{|l|}
63 \\
\end{tabular} \\
\hline$A_{15}$ & 106 & 100 & 126 & \begin{tabular}{|l|}
54 \\
\end{tabular} & 69 & 22 & 0 & 113 & 72 & \begin{tabular}{|l|}
129 \\
\end{tabular} \\
\hline$A_{16}$ & 83 & 108 & 0 & 0 & 50 & 25 & 16 & 144 & 21 & 0 \\
\hline$A_{21}$ & 12 & 12 & 20 & 12 & 20 & 12 & 12 & 12 & 12 & 20 \\
\hline$A_{31}$ & 48 & 72 & 120 & \begin{tabular}{|l|}
72 \\
\end{tabular} & 108 & 48 & 30 & 108 & 48 & 48 \\
\hline$A_{32}$ & 4 & 4 & 4 & 4 & 6 & 4 & 2 & 6 & 4 & 4 \\
\hline$A_{41}$ & 0 & 0 & 0 & 1 & 0 & 0 & 0 & 0 & 0 & 0 \\
\hline$B_{11}$ & 6 & 8 & 5 & 5 & 10 & 7 & 10 & 9 & 6 & \begin{tabular}{|l|}
10 \\
\end{tabular} \\
\hline$B_{21}$ & 9 & 7 & 7 & 7 & 7 & 7 & 7 & 8 & 7 & 9 \\
\hline$B_{22}$ & 5 & 5 & 5 & 6 & 9 & 5 & 5 & 9 & 5 & 8 \\
\hline$B_{31}$ & 80 & 85 & 90 & 90 & 95 & 75 & 75 & 85 & 80 & 95 \\
\hline$B_{32}$ & 85 & 85 & 85 & 80 & 95 & 70 & 75 & 80 & 80 & 95 \\
\hline$B_{33}$ & 85 & 85 & 85 & 85 & 95 & 80 & 75 & 85 & 85 & 95 \\
\hline$B_{34}$ & 80 & 80 & 85 & 95 & 95 & 75 & 75 & 80 & 80 & 95 \\
\hline$B_{35}$ & 80 & 85 & 85 & 85 & 95 & 80 & 95 & 80 & 80 & 95 \\
\hline$B_{41}$ & 82 & 62 & 53 & 67 & 91 & 72 & 58 & 72 & 96 & \begin{tabular}{|l|}
77 \\
\end{tabular} \\
\hline$B_{42}$ & 24 & 32 & 50 & 61 & 77 & 45 & 79 & 59 & 67 & 73 \\
\hline$B_{43}$ & 43 & 83 & 67 & \begin{tabular}{|l|}
50 \\
\end{tabular} & 67 & 50 & 67 & 81 & 75 & \begin{tabular}{|l|}
75 \\
\end{tabular} \\
\hline$C_{11}$ & 7.5 & 8 & 8 & 8 & 8 & 7.5 & 9 & 8 & 9 & 7 \\
\hline$C_{12}$ & 6 & 8 & 7 & 7 & 8 & 6 & 8 & 8.5 & 8.5 & 6 \\
\hline$D_{11}$ & 69 & 52 & 51 & 32 & 37 & 24 & 14 & 54 & 43 & 89 \\
\hline$E_{11}$ & 2 & 0 & 0 & 0 & 0 & 1 & 0 & 0 & 1 & 4 \\
\hline$E_{12}$ & 58 & 50 & 56 & \begin{tabular}{|l|}
74 \\
\end{tabular} & 50 & 70 & 51 & 47 & 44 & \begin{tabular}{|l|}
53 \\
\end{tabular} \\
\hline$E_{21}$ & 18 & \begin{tabular}{|l}
139 \\
\end{tabular} & 0 & \begin{tabular}{|l}
123 \\
\end{tabular} & \begin{tabular}{|l}
127 \\
\end{tabular} & 66 & 6 & 238 & 49 & 3 \\
\hline$E_{22}$ & 18 & \begin{tabular}{|l|}
139 \\
\end{tabular} & 0 & \begin{tabular}{|l|}
123 \\
\end{tabular} & 127 & 66 & 6 & 238 & 49 & 3 \\
\hline$E_{31}$ & 6 & 2 & 9 & 2 & 3 & 5 & 2 & 2 & 6 & 10 \\
\hline$E_{32}$ & 6 & 2 & 9 & 2 & 3 & 5 & 2 & 2 & 6 & 10 \\
\hline$E_{41}$ & 3 & 0 & 2 & 0 & 0 & 4 & 0 & 0 & 0 & 4 \\
\hline$E_{42}$ & 121000 & 0 & 204400 & 0 & 0 & \begin{tabular}{|l|}
1065000 \\
\end{tabular} & 0 & 0 & 0 & 1158360 \\
\hline$E_{51}$ & 369440 & 526100 & 7708478 & 0 & 415000 & 3742000 & 50000 & 913370 & 926000 & 988000 \\
\hline$E_{52}$ & 0 & 4 & 0 & 10 & 3 & 0 & 0 & 7 & 0 & 0 \\
\hline$E_{53}$ & 2 & 1 & 2 & 5 & 1 & 4 & 4 & 1 & 4 & 6 \\
\hline$E_{54}$ & 0 & 0 & 0 & 2 & 0 & 1 & 1 & 0 & 0 & 1 \\
\hline
\end{tabular}

TABLE X. The Grey Relational Grade and the Rank of Each DePartment and There Rank

\begin{tabular}{|l|l|l|l|l|l|l|l|l|l|l|}
\hline & A & Rank & B & Rank & C & Rank & D & Rank & E & Rank \\
\hline $\boldsymbol{G}_{\boldsymbol{I}}$ & 0.395 & 6 & 0.532 & 5 & 0.341 & 8 & 0.350 & 9 & 0.348 & 10 \\
\hline $\boldsymbol{G}_{\boldsymbol{2}}$ & 0.393 & 7 & 0.389 & 7 & 0.491 & 4 & 0.398 & 7 & 0.356 & 6 \\
\hline $\boldsymbol{G}_{\boldsymbol{3}}$ & 0.500 & 2 & 0.372 & 9 & 0.387 & 6 & 0.402 & 6 & 0.631 & 1 \\
\hline $\boldsymbol{G}_{\boldsymbol{4}}$ & 0.408 & 5 & 0.384 & 8 & 0.387 & 6 & 0.542 & 3 & 0.460 & 4 \\
\hline $\boldsymbol{G}_{\boldsymbol{5}}$ & 0.488 & 3 & 0.773 & 2 & 0.491 & 4 & 0.491 & 4 & 0.351 & 8 \\
\hline $\boldsymbol{G}_{\boldsymbol{6}}$ & 0.340 & 9 & 0.342 & 10 & 0.341 & 8 & 0.668 & 2 & 0.409 & 5 \\
\hline $\boldsymbol{G}_{\boldsymbol{7}}$ & 0.333 & 10 & 0.437 & 4 & 0.791 & 2 & 1.000 & 1 & 0.349 & 9 \\
\hline $\boldsymbol{G}_{\boldsymbol{g}}$ & 0.449 & 4 & 0.597 & 3 & 0.700 & 3 & 0.390 & 8 & 0.480 & 3 \\
\hline $\boldsymbol{G}_{\boldsymbol{9}}$ & 0.362 & 8 & 0.393 & 6 & 1.000 & 1 & 0.445 & 5 & 0.353 & 7 \\
\hline $\boldsymbol{G}_{\boldsymbol{1} \boldsymbol{0}}$ & 0.885 & 1 & 0.824 & 1 & 0.333 & 10 & 0.333 & 10 & 0.518 & 2 \\
\hline
\end{tabular}

TABLE XI. Cluster SCORE OF EACH Department AND THere RANK

\begin{tabular}{|c|c|c|}
\hline & Grey Relation Grade & Rank \\
\hline $\mathrm{G}_{1}$ & 0.387 & 9 \\
\hline $\mathrm{G}_{2}$ & 0.391 & 8 \\
\hline $\mathrm{G}_{3}$ & 0.513 & 2 \\
\hline $\mathrm{G}_{4}$ & 0.425 & 6 \\
\hline $\mathrm{G}_{5}$ & 0.474 & 4 \\
\hline $\mathrm{G}_{6}$ & 0.375 & 10 \\
\hline $\mathrm{G}_{7}$ & 0.421 & 7 \\
\hline $\mathrm{G}_{8}$ & 0.495 & 3 \\
\hline $\mathrm{G}_{9}$ & 0.428 & 5 \\
\hline $\mathrm{G}_{1}$ & 0.689 & 1 \\
\hline
\end{tabular}

The cluster score of each department and there rank is shown in "Table XI".

\section{CONCLUSION}

The present study combines AHP and GRA. First, by applying AHP, the researcher obtains the weight of the factors of each hierarchy. Next, by applying GRA, the researcher processes calculation of the measure between discrete series. The purpose of this study is to investigate and assess the management performance of each department. 
This study can serve as a guide for improving management performance of each department and enhancing competitiveness.

\section{A. Assess on the Basis of Elements Pertaining to Individual Offices}

Based on ranking of grey relational grade, the researcher analyzes two top-ranking departments and two lowestranking departments. The results are shown below

- Academic affairs office: The two top-ranking departments respectively have a relatively large number of students and they were previously conferred Grade A in the college/university accreditation. The two lowest-ranking departments respectively have a relatively small number of students and they were previously conferred Grade B in. the college/university accreditation

- Student affairs office: The top two departments excel in total student affairs, subsidy cases from the government, participation in school sports contest, teacher-student physical fitness examination, and character education and so on. The two lowestranking departments have relatively low degree of participation.

- General affairs office: As only property care and maintenance is assessed, there exists no significant difference between all departments.

- Personnel office: As far as teacher-student ratio is concerned, the top two departments respectively have the smallest number of students, while low-ranking departments are those with relatively a large number of students.

- Technological cooperation office: The assessment focuses on number of industry-based programs and amount of cooperation programs. The top two departments are exactly the top two departments in academic affairs. The two lowest-ranking departments differ considerably from other departments in the number and amount of industrybased joint programs.

It can be seen that the top-ranking departments excel in student recruitment. Compared with other departments, they have a larger number of new students and total students. Interestingly enough, the three departments, which previously won grade $\mathrm{A}$ in the college/university accreditation, also rank high in the assessment.

\section{B. Total Management Assessment}

Concerning assessment regarding academic, student and general affairs, Department G10 is No. 1 in ranking of Grey relational degrees. In contrast, Department G6 ranks low in assessment regarding all five affairs. It is true that even departments with higher teacher-student ratio are likely to be faced with student recruitment dismissal or closure. Therefore, ill-prepared departments are doomed to disappear from the educational arena. This is a measure based on economic consideration.

\section{REFERENCES}

[1] J. L. Deng, "An introduction to grey system theory, The Journal of Grey System, vol. 1, no. 1, pp. 1-24, 1989

[2] T. L. Saaty, The analytic hierarchy process, New York: McGraw-Hill, 1980

[3] T. W. Sheu, D. H. Pham, P. T. Nguyen, P. H. Nguyen amd M. Nagai, "RGSP Toolbox and application in education assessment," Open Journal of Communications And Software, vol.1, no.1, pp11-27,2014

[4] Q. S. Lin, Y. F. Lin, "The study of adaptive teaching schedule study in Internet by using grey prediction", Proc. of 4th Grey System Theory Conference, pp. 170-173, 1999.

[5] C. C. Lee, Y. z. Lee, The evaluation of significant for teaching service attributes quality in Environmental Education via grey relational analysis, National Kaohsiung University of Applied Science, vol. 9, no. 3, pp. 255-267, 2012.

[6] Y. R. Wang, F. M. Lee and Y. F. Chang, Discussion on Conflict Management and school administrative relationship between emotional intelligence, School Administration, vol. 34, pp. 70-84, 2004.

[7] P. T. Chen, Z. Y. Lee, H. C. Yu and G. H. Tzeng, "Analysis of the theoretical basis and practical applicability of a college teacher's achievement evaluation model: the case study of a national University in Hsinchu, Bulletin of Educational Research vol. 49, no. 4, pp. 191 218, 2003

[8] B. T. Wang, J. R. Wang, K. L. Wen, M. Nagai and J. C. Liang, Kansei engineering fundamentals, Taiwan Kansei Information Association, Taichung, 2011.

[9] C. L. Lin, Y. F. Huang, C. H. Lin, H. S. Lin and K. L. Wen, "Utilize the idea of loss function to develop the new grey generating models and computer toolbox," Proc. of 10th Grey System Theory Conference, pp. 71-76, 2005.

[10] K. L. Wen, Grey system theory, 2nd Edition, Wunan Publisher, Taipei, 2013 